\title{
Does Endourological Intervention a Suitable Treatment Options in Management of Iatrogenic Thermal Ureteral Injury?
}

\author{
Oguz Ozden Cebeci ${ }^{1}$ and Tayyar Alp Özkan ${ }^{2}$ \\ ${ }^{1}$ Saglik Bilimleri Universitesi \\ ${ }^{2}$ Acibadem Hospitals Group
}

March 12, 2021

\begin{abstract}
Introduction This study aimed to evaluate the etiological factors and their effects on long-term clinical outcomes in patients with iatrogenic ureteral injury (IUI). Material and Method Twenty-seven patients who underwent surgery because of IUI were evaluated between January 2011 and April 2018. Patients were classified according to the time of diagnosis and the need for reoperation after the urologic intervention. The IUI cases detected during gynecological surgery were called 'perioperative' IUI, and those diagnosed late as 'postoperative' (delayed) IUI. The IUI type was categorized as 'cold transection' due to surgical dissection or ligation and 'thermal injury' if it depended on any energy-based surgical device. Results Postoperative diagnosed cases consisted of exclusively after laparoscopic surgery $(\mathrm{p}=.025)$. Patients with thermal injury to the ureter were mostly diagnosed postoperatively $(\mathrm{p}=.021)$. Patients who underwent endourological intervention, $31.25 \%(\mathrm{~N}=5 / 16)$ were diagnosed during gynecologic surgery, and $68.75 \%(\mathrm{n}=11 / 16)$ were diagnosed postoperatively. For open reconstructive surgery, these rates were observed to be $72.72 \%(\mathrm{n}=8 / 11)$ and $27.28 \%(\mathrm{n}=3 / 11)$, respectively $(\mathrm{p}=.034)$. IUI was due to thermal injury in all patients who developed complications after the urological intervention $(\mathrm{p}=.046)$, and the first urological intervention was endoscopic double loop stenting $(\mathrm{p}=.005)$. One of these patients was diagnosed in the perioperative period and seven in the postoperatively $(\mathrm{p}=.016)$. Conclusion Treatment success rates are low in patients who underwent endourological intervention after thermal IUI. Therefore, surgical techniques in which the traumatic ureter segment is excised should be preferred to avoid complications. Key Words Ureter, Iatrogenic, Thermal Injury, Iatrogenic Ureteral Injury, Endourological Intervention.
\end{abstract}

Does Endourological ntervention a Suitable Treatment Options in Management of atrogenic Thermal Ureteral Injury?

\section{Abstract \\ Introduction}

This study aimed to evaluate the etiological factors and their effects on long-term clinical outcomes in patients with iatrogenic ureteral injury (IUI).

\section{Material and Method}

Twenty-seven patients who underwent surgery because of IUI were evaluated between January 2011 and April 2018. Patients were classified according to the time of diagnosis and the need for reoperation after the urologic intervention. The IUI cases detected during gynecological surgery were called 'perioperative' IUI, and those diagnosed late as 'postoperative' (delayed) IUI. The IUI type was categorized as 'cold transection' due to surgical dissection or ligation and 'thermal injury' if it depended on any energy-based surgical device.

\section{Results}


Postoperative diagnosed cases consisted of exclusively after laparoscopic surgery $(\mathrm{p}=.025)$. Patients with thermal injury to the ureter were mostly diagnosed postoperatively $(\mathrm{p}=.021)$. Patients who underwent endourological intervention, $31.25 \%(\mathrm{~N}=5 / 16)$ were diagnosed during gynecologic surgery, and $68.75 \%$ (n $=11 / 16)$ were diagnosed postoperatively. For open reconstructive surgery, these rates were observed to be $72.72 \%(\mathrm{n}=8 / 11)$ and $27.28 \%(\mathrm{n}=3 / 11)$, respectively $(\mathrm{p}=.034)$. IUI was due to thermal injury in all patients who developed complications after the urological intervention $(\mathrm{p}=.046)$, and the first urological intervention was endoscopic double loop stenting $(\mathrm{p}=.005)$. One of these patients was diagnosed in the perioperative period and seven in the postoperatively $(\mathrm{p}=.016)$.

\section{Conclusion}

Treatment success rates are low in patients who underwent endourological intervention after thermal IUI. Therefore, surgical techniques in which the traumatic ureter segment is excised should be preferred to avoid complications.

\section{Key Words}

Iatrogenic, Ureter, Thermal Injury, Iatrogenic Ureteral Injury, Endourological Intervention.

\section{Introduction}

Ureter runs in the major pelvis over the iliac vessels and through the uterine artery; thus, it is vulnerable to iatrogenic damage in pelvic surgery (1). Owing to the rise in the total number of surgical procedures and the widespread use of minimally invasive surgical methods, the occurrence of iatrogenic ureteral injury (IUI) has increased $(2,3)$. Non-urologic IUI cases are often detected post gynecological surgery (4). The frequency of IUI is greater than that of open surgery following laparoscopic hysterectomy (5). Ureter is commonly injured in the lower $1 / 3$ segment, located between the uterine artery and ureterovesical junction (6).

Early diagnosis and immediate repair can minimize ureter-related complications during long-term follow-up (7), although most cases can be detected in the postoperative period (8). The location of the traumatic segment and the type of injury are decisive for the surgical approach chosen for the treatment (9). Ureteroureterostomy or ureteral reimplantation is recommended for the middle and distal ureteral injury $(10,11)$. However, some studies suggest endourological intervention for first-line treatment in the IUI (12-15). The success rates have been documented across such a broad spectrum due to the heterogeneity of IUI etiology, the low density of cases, and the diversity of treatment options (17-84\%) (13-18).

here is no study investigating the effect of treatment results according to injury types the ureter. We aimed to evaluate the etiological factors and their effects on long-term clinical outcomes in patients with IUI.

\section{Material and Method}

We retrospectively analyzed the medical record of twenty-seven patients who underwent surgical intervention for IUI in our centers between January 2011 and April 2018.

Patients were classified according to the time of diagnosis and the need for reoperation after the urologic intervention. The following attributes were analyzed for each patient: previous surgery, cause of gynecological surgery, gynecological surgical procedure, time of diagnosis, urological intervention, and post-urological complication. The IUI cases detected during gynecological surgery were called 'perioperative' IUI, and those diagnosed late as 'postoperative' (delayed) IUI.

The IUI type was categorized as 'cold transection' due to surgical dissection or ligation and 'thermal injury' if it depended on any energy-based surgical device. Ultracision Harmonic Scalpel@) (Ethicon, Cincinnati, $\mathrm{OH}$ ) was used for surgical dissection and coagulation in all patients with thermal injury.

Two surgeons performed all urologic interventions. All perioperative diagnosed patients were followed-up by the same surgeon who performed urological intervention. The delayed diagnosed group was presented symptoms including vaginal serous discharge, localized urinoma, renal colic, low urine volume, or pelvic pain. 
Patients were evaluated either by contrast-enhanced computed tomography urography or intravenous urography. A retrograde urethrography and ureterorenoscopy (4.5 Fr, Richard Wolf, Knittlingen Germany) were performed for the scope of the ureteral injury. An open-end $4.8 \mathrm{~F} 26 \mathrm{~cm}$ double loop ureteral stent (Coloplast Vortek $($ ) ) was placed with a 0.035-inch diameter hydrophilic coated guidewire (Cook RoadRunner@) under fluoroscopy for the endoscopically treated patients. The endoscopically treated patients were discharged the same day following outpatient surgery.

Ureteroneocystostomy (UNC) was performed using the Lich Gregoir technique in the open repair group. A urethral catheter was placed in the patients of the Open repair group for one week. The open surgery group was discharged on the second postoperative day or later when it is appropriate. Stents were removed at postoperative sixth and 12th week for the open surgery and endoscopic treatment groups.

All Patients were scheduled for a follow-up protocol and evaluated with a urinalysis, renal function tests, renal ultrasound, and physical examination bi-annually. No patients were lost to follow-up.

Histogram and the Shapiro-Wilk's test were used to test whether variables were normally distributed or not. Descriptive analyses were presented using the mean \pm standard deviation or median (Interquartile range [IQR]). The chi-square test was used to compare categories, and the t-test was used for continuous variables. All analyses were performed using STATA 14.2 (StataCorp, TX). Statistical significance was set at 0.05, and all tests were two-tailed.

\section{Results}

All cases developed during or after gynecological surgery, and the ureter was injured of its $1 / 3$ distal segment. Of the patients, $48.15 \%(\mathrm{n}=13 / 27)$ were diagnosed perioperatively and $51.85 \%(\mathrm{n}=14 / 27)$ had delayed diagnosis (postoperatively). The in the delayed group was $13 \pm 8.6$ days (detailed demographic and clinical characteristics of the patients are summarized in Table 1).

Postoperative diagnosed patients consisted exclusively after laparoscopic surgery ( $\mathrm{p}=.025)$ (Table 2). In the perioperative time, $85.71 \%(\mathrm{n}=6 / 7)$ of cold transection type IUI patients were diagnosed. However, patients with thermal injury to the ureter were mostly diagnosed postoperatively $(\mathrm{p}=.021)$ (Table 2$)$.

Patients who underwent minimally invasive approach in their urological interventions, $31.25 \%(\mathrm{~N}=5 / 16)$ were diagnosed during gynecologic surgery and $68.75 \%(n=11 / 16)$ were diagnosed postoperatively. In comparison, in patients who underwent open reconstructive surgery, these rates were observed to be 72.72 $\%(\mathrm{n}=8 / 11)$ and $27.28 \%(\mathrm{n}=3 / 11)$ respectively $(\mathrm{p}=.034)$ (Table 2$)$.

Complications after urological intervention were categorized using the Clavien-Dindo classification system (19). We detected eight grade $3 \mathrm{~b}$ complications in patients.

In all of these eight cases, IUI was due to thermal injury $(\mathrm{p}=.046)$, and the first urological intervention was endoscopic double loop stenting $(\mathrm{p}=.005)$ (Table 3$)$. One of these patients was diagnosed in the perioperative period, and seven in the postoperatively $(\mathrm{p}=.016)$ (Table 3$)$. The ureteral stricture was developed in six of these seven patients, and a ureterovaginal fistula was seen in one ( Table 1).

Lich Gregoir ureteroneocystostomy was performed in five of these eight patients, and no postoperative complications occurred in the follow-up. Three patients with ureteral stricture did not consent to open or laparoscopic ureteral reimplantation. These patients were followed up with repetitive ureteral dilatations and double loop stents to protect the renal unit. No renal dysfunction or hydronephrosis was observed at a median follow-up of 58.5 months (IQR: 46.5-67) (Table 1).

\section{Discussion}

Our research has that the type of ureteral injury is a crucial factor in urological intervention decisions and treatment efficacy in IUI. We observed that it was more often diagnosed in the postoperative period if IUI 
was caused by thermal injury. Endourological interventions were performed more frequently in cases, and half of those procedures required repeated urological interventions.

IUI incidence has increased due to the rise in the overall number of surgeries and the widespread use of minimally invasive surgical techniques $(2,3)$. The most common causes of ureteral trauma are suture ligation, blunt injury, partial/total transection, and ischemia due to thermal damage (20). Early detection of trauma and immediate ureteral correction surgery reduces kidney and ureter related complications $(7$, 21). In postoperative IUI cases, sepsis (Odds Ratio: 11.9), urinary fistula (Odds Ratio: 23.8), and mortality (Odds Ratio: 1.4) are more common than those diagnosed perioperatively (22). More repetitive urological interventions may be required in (23).

Approximately three-quarters of IUI malpractice litigation end up against surgeons. Prolonged urinary leakage, delayed ureteral reconstruction, inattentive postoperative care, and insufficient surgical training are the most common accusations (24). Therefore, it is essential to choose the appropriate treatment in IUI.

The recommended treatment in IUI is ureteroureterostomy or ureteral reimplantation according to the traumatic ureter segment $(8,10,11,25)$. However, endourological approaches are often chosen as initial care due to short hospital stay, fewer complication, and low treatment cost (26). Reported success rates for endoscopic IUI management range from $17 \%$ to $84 \%$ (13-18). In study, we initially treated $59.25 \%$ ( $\mathrm{n}=$ $16 / 27$ ) of the patients with endourological methods.

Endourological intervention recommended in patients with a ureteral stenosis segment smaller than $2 \mathrm{~cm}$ or a small fistula tract with a mostly preserved ureter wall (16). Successful results have been reported antegrade stent approach with endoscopic 'rendezvous' method in patients diagnosed with postoperative IUI (12). Delayed diagnosed IUI treated with endoscopic realignment for partial or complete transected ureter in 11 patients had a $45.46 \%(\mathrm{n}=5 / 11)$ ureteral stricture at the follow-up. The authors concluded that ureteral stenosis frequency is high in IUI cases, and patient selection is the main factor for treatment success (14). $1185(\mathrm{n}=9 / 76)$ of the cases due to thermal injury and others to suture ligation (18). In a study including 76 IUI cases, 29 patients diagnosed during the perioperative period underwent open reconstructive surgery, and all recovered without complications. Forty-seven patients were diagnosed late, a double loop stent was placed with an endourological approach, and only seven of these recovered without complications (27).

In studies, the type of ureteral injury was not specified. Because of the heterogeneity in IUI etiology, the low incidence of cases, and the variety of treatment choices, success rates of treatment results may have spread over a wide range.

There are a limited number of publications investigating IUI due to thermal damage (28). Tissue coagulation devices that work with ultrasonic-based energy vary depending on the device's technical features but can cause an increased temperature between $33-100^{\circ} \mathrm{C}$ on the surrounding tissue (29) and lateral spread may $10 \mathrm{~mm}$. In ultrasonically activated electrocautery, the temperature rises very quickly up to $350{ }^{\circ} \mathrm{C}$, and the lateral spread can reach up to $22 \mathrm{~mm}$ (30). These tissue heat quantities are higher than $60^{\circ} \mathrm{C}$, even at $25 \mathrm{~mm}$ from the device. Therefore, it has been shown that ultrasonic electrocoagulation devices causes significant histological damage in thin-walled organs such as the ureter, which cannot be detected macroscopically (31). While performing thermal ablation of a mass in the renal hilum, it has been reported that ureteropelvic junction stenosis developed in the postoperative follow-up due to thermal damage without any perioperative complications (32).

We detected $85.71 \%(\mathrm{n}=6 / 7)$ of patients with cold transection IUI during gynecological surgery. This rate was $35 \%(\mathrm{n}=7 / 20)$ in thermal injuries, which was statistically significantly lower than cold transection (Table 2). Almost one-third of the thermal injuries could not recognize perioperative settings, supporting previous studies (31). Thermal injury cases were mostly treated endoscopically and had higher complication rates than the cold transection IUI (Table 3).

We believe that high complication rates are observed in patients treated with endourological intervention after thermal IUI since the traumatic ureter segment was not excised. Although the endoscopic surgical 
method did not fail in the early period, we observed complications due to ureter in half of the patients during follow-up. Therefore, in our opinion, surgical techniques in which the traumatic part of ureter is excised should be preferred in suspected thermal IUI cases to avoid complications (such as stricture or fistula).

The study's limitations are the retrospective nature and a low number of cases due to IUI characteristics, and the lack of knowledge of the energy setup of energy-based surgical instruments used during ureter dissection.

\section{Conclusion:}

Urologists perform the endourological intervention in delayed diagnosed IUI treatment due to short operative time hospital stay, fewer complication, and low treatment cost. The perioperative recognition rate and endourological intervention treatment success rates of thermal IUI are limited. The possibility of thermal damage should be kept in mind in complications such as urinary leakage and hydronephrosis due to ureteral stricture, which occurs in the late period during postoperative follow-up. If IUI develops in the presence or suspicion of thermal damage, excising the traumatic segment and ensuring ureter continuity (such as ureteroureterostomy, ureteral reimplantation) increases the success of surgical treatment, regardless of the level of ureteral damage.

\section{References}

1. Raassen T, Ngongo CJ, Mahendeka MM. Diagnosis and management of 365 ureteric injuries following obstetric and gynecologic surgery in resource-limited settings. Int Urogynecol J. 2018;29(9):1303-9.

2. Parpala-Spårman T, Paananen I, Santala M, Ohtonen P, Hellström P. Increasing numbers of ureteric injuries after the introduction of laparoscopic surgery. Scand J Urol Nephrol. 2008;42(5):422-7.

3. Assimos DG, Patterson LC, Taylor CL. Changing incidence and etiology of iatrogenic ureteral injuries. J Urol. 1994;152(6 Pt 2):2240-6.

4. Gilmour DT, Das S, Flowerdew G. Rates of urinary tract injury from gynecologic surgery and the role of intraoperative cystoscopy. Obstet Gynecol. 2006;107(6):1366-72.

5. Härkki-Sirén P, Sjöberg J, Tiitinen A. Urinary tract injuries after hysterectomy. Obstet Gynecol. 1998;92(1):113-8.

6. Gild P, Kluth LA, Vetterlein MW, Engel O, Chun FKH, Fisch M. Adult iatrogenic ureteral injury and stricture-incidence and treatment strategies. Asian J Urol. 2018;5(2):101-6.

7. Selzman AA, Spirnak JP. Iatrogenic ureteral injuries: a 20-year experience in treating 165 injuries. J Urol. 1996;155(3):878-81.

8. Burks FN, Santucci RA. Management of iatrogenic ureteral injury. Ther Adv Urol. 2014;6(3):115-24.

9. Mendez LE. Iatrogenic injuries in gynecologic cancer surgery. Surg Clin North Am. 2001;81(4):897-923.

10. Serafetinides E, Kitrey ND, Djakovic N, Kuehhas FE, Lumen N, Sharma DM, et al. Review of the current management of upper urinary tract injuries by the EAU Trauma Guidelines Panel. Eur Urol. 2015;67(5):9306.

11. Zinman LN, Vanni AJ. Surgical Management of Urologic Trauma and Iatrogenic Injuries. Surg Clin North Am. 2016;96(3):425-39.

12. Pastore AL, Palleschi G, Silvestri L, Leto A, Autieri D, Ripoli A, et al. Endoscopic rendezvous procedure for ureteral iatrogenic detachment: report of a case series with long-term outcomes. J Endourol. 2015;29(4):415-20.

13. Narang V, Sinha T, Karan SC, Sandhu AS, Sethi GS, Srivastava A, et al. Ureteroscopy: savior to the gynecologist? Ureteroscopic management of post laparoscopic-assisted vaginal hysterectomy ureterovaginal fistulas. J Minim Invasive Gynecol. 2007;14(3):345-7. 
14. Choi YS, Lee SH, Cho HJ, Lee DH, Kim KS. Outcomes of ureteroscopic double-J ureteral stenting for distal ureteral injury after gynecologic surgery. Int Urogynecol J. 2018;29(9):1397-402.

15. Chung D, Briggs J, Turney BW, Tapping CR. Management of iatrogenic ureteric injury with retrograde ureteric stenting: an analysis of factors affecting technical success and long-term outcome. Acta Radiol. 2017;58(2):170-5.

16. Cormio L, Battaglia M, Traficante A, Selvaggi FP. Endourological treatment of ureteric injuries. Br J Urol. 1993;72(2):165-8.

17. Kim JS, Lee DH, Suh HJ. Double-J stenting: initial management of injured ureters recognized late after gynecological surgery. Int Urogynecol J. 2010;21(6):699-703.

18. Koukouras D, Petsas T, Liatsikos E, Kallidonis P, Sdralis EK, Adonakis G, et al. Percutaneous minimally invasive management of iatrogenic ureteral injuries. J Endourol. 2010;24(12):1921-7.

19. Dindo D, Demartines N, Clavien PA. Classification of surgical complications: a new proposal with evaluation in a cohort of 6336 patients and results of a survey. Ann Surg. 2004;240(2):205-13.

20. Brandes S, Coburn M, Armenakas N, McAninch J. Diagnosis and management of ureteric injury: an evidence-based analysis. BJU Int. 2004;94(3):277-89.

21. Al-Awadi K, Kehinde EO, Al-Hunayan A, Al-Khayat A. Iatrogenic ureteric injuries: incidence, aetiological factors and the effect of early management on subsequent outcome. Int Urol Nephrol. 2005;37(2):235-41.

22. Blackwell RH, Kirshenbaum EJ, Shah AS, Kuo PC, Gupta GN, Turk TMT. Complications of Recognized and Unrecognized Iatrogenic Ureteral Injury at Time of Hysterectomy: A Population Based Analysis. J Urol. 2018;199(6):1540-5.

23. Kominsky HD, Shah NC, Beecroft NJ, Diab D, Crescenze IM, Posid T, et al. Does Timing of Diagnosis and Management of Iatrogenic Ureter Injuries Affect Outcomes? Experience From a Tertiary Center. Urology. 2020 .

24. Bole R, Linder BJ, Gopalakrishna A, Kuang R, Boon AL, Habermann EB, et al. Malpractice Litigation in Iatrogenic Ureteral Injury: A Legal Database Review. Urology. 2020.

25. Sahai A, Symes AJ, Challacombe BJ, Glass JM, Popert RJ, Dasgupta P. Laparoscopic ureteroneocystostomy for benign lower ureteric stricture: case study and literature review. Int J Clin Pract Suppl. 2005(147):115-7.

26. Tyritzis SI, Wiklund NP. Ureteral strictures revisited... trying to see the light at the end of the tunnel: a comprehensive review. J Endourol. 2015;29(2):124-36.

27. Sakellariou P, Protopapas AG, Voulgaris Z, Kyritsis N, Rodolakis A, Vlachos G, et al. Management of ureteric injuries during gynecological operations: 10 years experience. Eur J Obstet Gynecol Reprod Biol. 2002;101(2):179-84.

28. Selli C, Turri FM, Gabellieri C, Manassero F, De Maria M, Mogorovich A. Delayed-onset ureteral lesions due to thermal energy: an emerging condition. Arch Ital Urol Androl. 2014;86(2):152-3.

29. Kim JS, Hattori R, Yamamoto T, Yoshino Y, Gotoh M. How can we safely use ultrasonic laparoscopic coagulating shears? Int J Urol. 2010;17(4):377-81.

30. Kinoshita T, Kanehira E, Omura K, Kawakami K, Watanabe Y. Experimental study on heat production by a $23.5-\mathrm{kHz}$ ultrasonically activated device for endoscopic surgery. Surg Endosc. 1999;13(6):621-5.

31. Emam TA, Cuschieri A. How safe is high-power ultrasonic dissection? Ann Surg. 2003;237(2):186-91.

32. Johnson DB, Saboorian MH, Duchene DA, Ogan K, Cadeddu JA. Nephrectomy after radiofrequency ablation-induced ureteropelvic junction obstruction: potential complication and long-term assessment of 
ablation adequacy. Urology. 2003;62(2):351-2.

\begin{tabular}{|c|c|c|c|c|c|c|}
\hline Pts & Age & Previous surgery & Gynecologic procedure & Pathology & Type of Ureteral injury & Side \\
\hline 1 & 53 & No & LHS & Myoma uteri & Cold transection & $\mathrm{R}$ \\
\hline 2 & 64 & No & OHS & Endometrium Carcinoma & Thermal injury & $\mathrm{R}$ \\
\hline 3 & 53 & No & OHS & Endometrium Carcinoma & Thermal injury & $\mathrm{R}$ \\
\hline 4 & 54 & Apendectomy & OHS & Teratoma & Cold transection & $\mathrm{R}$ \\
\hline 5 & 53 & No & LHS & Myoma uteri & Thermal injury & $\mathrm{R}$ \\
\hline 6 & 45 & No & LHS & Myoma uteri & Thermal injury & $\mathrm{R}$ \\
\hline 7 & 63 & No & LHS & Endometrium Carcinoma & Thermal injury & $\mathrm{R}$ \\
\hline 8 & 37 & Myomectomy & OHS & Myoma uteri & Thermal injury & $\mathrm{R}$ \\
\hline 9 & 61 & No & LHS & Myoma uteri & Thermal injury & $\mathrm{R}$ \\
\hline 10 & 50 & Apendectomy & LHS & Myoma uteri & Thermal injury & $\mathrm{R}$ \\
\hline 11 & 51 & No & LHS & Myoma uteri & Cold transection & $\mathrm{R}$ \\
\hline 12 & 55 & No & LHS & Myoma uteri & Thermal injury & $\mathrm{R}$ \\
\hline 13 & 45 & No & LHS & Cervix Carcinoma & Thermal injury & $\mathrm{R}$ \\
\hline 14 & 55 & No & LHS & Myoma uteri & Thermal injury & $\mathrm{R}$ \\
\hline 15 & 51 & No & LHS & Endometriozis & Cold transection & $\mathrm{R}$ \\
\hline 16 & 59 & No & LHS & Myoma uteri & Thermal injury & $\mathrm{R}$ \\
\hline 17 & 52 & Apendectomy & LHS & Myoma uteri & Thermal injury & $\mathrm{R}$ \\
\hline 18 & 56 & No & OHS & Endometriosis & Cold transection & $\mathrm{R}$ \\
\hline 19 & 41 & No & LHS & Myoma uteri & Thermal injury & $\mathrm{R}$ \\
\hline 20 & 48 & No & LHS & Uterine bleeding & Thermal injury & $\mathrm{L}$ \\
\hline 21 & 47 & Apendectomy & LHS & Cervix Carcinoma & Thermal injury & $\mathrm{L}$ \\
\hline 22 & 57 & No & LHS & Cervix Carcinoma & Thermal injury & $\mathrm{L}$ \\
\hline 23 & 52 & No & LHS & Myoma uteri & Thermal injury & $\mathrm{L}$ \\
\hline 24 & 47 & No & LHS & Endometriosis & Cold transection & $\mathrm{L}$ \\
\hline 25 & 50 & No & LHS & Myoma uteri & Cold transection & $\mathrm{L}$ \\
\hline 26 & 64 & No & LHS & Endometrium Carcinoma & Thermal injury & $\mathrm{L}$ \\
\hline 27 & 45 & No & LHS & Myoma uteri & Thermal injury & $\mathrm{R}$ \\
\hline
\end{tabular}

Table 1: Detailed patient characteristics with individual surgical and follow-up outcomes.

Abbreviations:

LHS: Laparoscopic hysterectomy OHS: Open hysterectomy

UVF: Ureterovaginal fistula UNC: Ureteroneocystostomy

Table 2: Comparison of the clinical parameters of the cases according to the time of diagnosis.

Previous surgery n (\%)

No surgery

Perioperative diagnosis $(\mathrm{n}=13)$

Delayed diag

Abdominal surgery

$9(40.9)$

$4(80)$

$13(59.1)$

Cause of gynecologic surgery n (\%)

Malign + Endometriosis

$5(45.45)$

$1(20)$

Benign

$8(50)$

$6(54.55)$

Gynecologic procedure n (\%)

Abdominal surgery

$4(100)$

$8(50)$

Laparoscopic Surgery

9 (39.13)

0

Type of ureteral injury n (\%)

$14(60.87)$ 
Cold transection

Thermal injury

Urological intervention n (\%)

Endoscopic

Reconsturictive surgery

Complications of after urological interventions $\mathrm{n}(\%)$

No

Yes
$6(85.71)$

$7(35)$

$5(31.25)$

$8(72.72)$

Complications of after urological interventions $\mathrm{n}(\%)$

$12(63.15)$

$1(12.5)$
$1(14.29)$

$13(65)$

$11(68.75)$

$3(27.28)$

$7(36.85)$

$7(87.5)$

Previous surgery n (\%)

Yes

No

$1(20)$

$7(31.82)$

$4(80)$

Cause of gynecologic surgery n $(\%)$

Benign

$5(31.25)$

$3(27.27)$

$11(68.75)$

Malign + Endometriosis

$3(27.27)$

Gynecologic procedure (\%)

Abdominal hysterectomy

0

Laparoscopic hysterectomy

$8(34.78)$

$15(65.22)$

Type of ureteral injury $n(\%)$

Cold transection

0

Thermal injury

Time of diagnosis n (\%)

Perioperative

$1(7.69)$

$12(60)$

Delayed

$7(50)$

$12(92.31)$

Urological intervention n (\%)

Endoscopic

Reconstructive surgery

0

$8(50)$

$11(100)$

Table 3: Factors affecting complications after the urological intervention.

\section{Hosted file}

Table 3: Factor affecting complications after urological intervention.pdf available at https://authorea.com/users/357671/articles/513343-does-endourological-intervention-asuitable-treatment-options-in-management-of-iatrogenic-thermal-ureteral-injury 